\title{
Patient preference for and satisfaction with inhaler devices
}

\author{
P. Anderson
}

\begin{abstract}
Preference for and satisfaction with inhaler devices may be associated with improved clinical outcomes, but this has not been proven to date.

A screened Medline search for papers on preference for inhaler devices produced 29 studies on a variety of devices, with Advair Diskus ${ }$ and Turbuhaler $^{\mathrm{TM}}$ featuring prominently. Of the 23 studies sponsored by the pharmaceutical industry, the sponsor's device was preferred in 19. Interpretation of results was made more difficult because only two studies used robust instruments for measuring preference and satisfaction. Patients with unstable disease or who were unable to use inhalers were usually excluded, and the extent of instruction and coaching given in the studies was greater than that seen in everyday practice. Studies found no significant differences in clinical outcomes between devices (where measured).

Although inhaler preference is a valid patient-reported outcome deserving of scientific study, assessment and reporting of preference outcomes should follow the same regulatory standards as other patient-reported outcomes.
\end{abstract}

KEYWORDS: Asthma, chronic obstructive pulmonary disease, inhaler, preference, satisfaction atient preference for a particular inhaler device is a legitimate outcome for inclusion in studies of aerosolised drugs. However, this type of outcome is studied less frequently than other patient-reported outcomes, such as health-related quality of life (HRQL). There has been increased interest in the area of patient preference and satisfaction over the past decade, as preference for a particular medication or inhaler device may be associated with improved adherence with therapeutic regimens. Recent evidence-based guidelines for device selection and outcomes of aerosol therapy found that all of the devices studied worked equally well in patients who could use them appropriately [1]. The guidelines pointed out the importance of tailoring the device to the patient and recommended considering the following questions when selecting an inhaler device. 1) In what device is the drug available? 2) What device is the patient likely to be able to use properly, given their age and the clinical setting? 3) For which device and drug combination is reimbursement available? 4) Which are the cheapest devices? 5) Can all types of prescribed inhaled drugs be delivered with the same type of device? 6) Which are the most convenient devices for the patient, family or medical staff to use? 7) Does the patient or clinician have any specific device preferences? Preference for a device may be highly influenced by the clinical benefit (drug), economics, ease of use, dosing schedule, portability, taste, adverse effects and sociocultural factors, such as beliefs, knowledge and education.

\section{THE LINK BETWEEN DEVICE PREFERENCE AND PATIENT SATISFACTION}

Why measure inhaler preference? It is suggested that patients who use their preferred inhaler may obtain a greater degree of satisfaction with therapy, which should be an important advantage for both patients and caregivers. In addition, with the current emphasis on the patient as consumer, pharmaceutical and medical device manufacturers are increasingly interested in obtaining feedback about their product from patients. Showing greater satisfaction with one device compared with another provides a marketing advantage and the feedback can also be used to improve products. There is also the inference that increased satisfaction will lead to increased adherence, better clinical outcomes and reduced healthcare expenditures, but data for these associations are lacking. It is increasingly common for pharmaceutical companies to add a preference assessment to multicentre clinical trials of inhaled drugs, using another drugdevice combination as a comparator.

\section{SELECTION OF STUDIES FOR REVIEW}

The literature on inhaler device preference was reviewed by performing a Medline search using
CORRESPONDENCE

P. Anderson

Division of Pulmonary and Critical Care Medicine University of Arkansas for Medical Sciences

Central Arkansas Veterans Healthcare System

4301 W. Markham

Slot 555

Little Rock

AR 7220

USA

Fax: 15016867893

E-mail: PJAnderson@uams.edu 
the terms "inhaler", "preference", "satisfaction" and "acceptability", then searching specific device names. All studies in patients with asthma, chronic obstructive pulmonary disease (COPD) or obstructive lung disease (OLD) were included; review articles were excluded, as were studies on nebuliser therapy, those that involved only paediatric patients and those published in a language other than English. This screening process resulted in 29 papers being reviewed for the following elements: disease type, number of patients, duration and design of trial, comparator device, assessment tools, clinical outcomes measured, preferred device and presence of industry sponsorship. The trials were grouped according to type of device comparisons and industry sponsorship.

\section{SUMMARY OF RESULTS}

Two trials involved multiple device comparisons (table 1) [2, 3]. They both involved subjects with OLD and tested seven devices on a single occasion with instruction and handling, after which patients' preferences were ranked and their technique assessed. Neither of these trials had industry sponsorship.

A second group of 10 trials were sponsored by GlaxoSmithKline in subjects with asthma and/or COPD, and involved comparison of the Diskus ${ }^{\circledR}$ (GlaxoSmithKline, Brentford, UK) dry powder device with other inhalers (table 2) [4-13]. Four of the 10 Diskus $_{\circledR}$ trials were conducted as a single interview and device demonstration, and in two of these, there was no actual inhalation from the device. The remainder of the trials were of several weeks' duration and a short questionnaire was used to assess preference. In two Diskus ${ }_{\circledR}$ trials, a longacting $\beta_{2}$-agonist in the Diskus ${ }^{\circledR}$ was compared with a shortacting $\beta_{2}$-agonist in a pressurised metered-dose inhaler (pMDI) $[9,12]$. In nine of the 10 trials, the Diskus ${ }_{\circledR}$ was the preferred device when overall preference was assessed.

The next large group of trials involved comparisons with the dry powder inhaler, Turbuhaler ${ }^{\mathrm{TM}}$ (AstraZeneca, Lund, Sweden; table 3) [14-24]. This group included 11 trials, all in asthma patients; nine of them were sponsored by AstraZeneca. The Turbuhaler ${ }^{\mathrm{TM}}$ trials were $2-8$ weeks in duration and all but one employed a randomised, cross-over design. Various drugs were used in the devices, including terbutaline, budesonide, formoterol, salbutamol, flunisolide, fluticasone and beclomethasone. Only four of the 11 trials used the same drug in the two devices being compared; the others compared different drugs of the same class, such as inhaled corticosteroids, or short- or long-acting bronchodilators. The assessments were primarily made by questionnaire and one study used a 25-item questionnaire developed according to standards of psychometric testing (Patient Device Experience Assessment (PDEA)) by an independent outcomes research organisation [20]. In seven of the nine trials sponsored by AstraZeneca, the Turbuhaler $^{\mathrm{TM}}$ was the preferred device when overall preference was assessed.

A final group of six trials involved a variety of other devices (table 4) [25-30]. One trial, sponsored by Boehringer Ingelheim $\mathrm{GmbH}$, compared the Respimat ${ }^{\circledR}$ Soft Mist $^{\mathrm{TM}}$ Inhaler (Boehringer Ingelheim $\mathrm{GmbH} \& \mathrm{Co}$. KG, Ingelheim, Germany) with a pMDI, using a validated questionnaire (the Patient Satisfaction and Preference Questionnaire (PASAPQ)) in patients with asthma and COPD [25]. Another trial in this group compared Autohaler ${ }^{\mathrm{TM}}$ (3M Pharmaceuticals, St Paul, MN, USA) with a pMDI in asthma and measured whether patient opinion about a device affected compliance with medication (as measured by canister weight) [29]. In this trial, patients preferred the Autohaler ${ }^{\mathrm{TM}}$, but this preference did not translate into better compliance compared with the pMDI. Greater treatment frequency did, however, have a negative influence on compliance.

In general, for all 29 studies described, there were no significant differences in clinical outcomes between devices (when these were measured). In addition, patients with unstable disease or those unable to use the inhalers were usually excluded from the studies. Inhaler technique was instructed and observed but variably scored, and the majority of the preference assessments were short questionnaires with open-answer questions that were administered at the end of each study period in cross-over studies and then at study conclusion. Of the 29 studies, 23 were sponsored by the pharmaceutical industry, and $83 \%$ of the sponsored trials favoured the device manufactured by the sponsoring company.

\section{INTERPRETATION AND DISCUSSION}

The science of studying "preference" for and "satisfaction" with medication or a device is relatively new. The approach and techniques, however, should be the same as when measuring other patient-reported outcomes, such as HRQL. Treatment satisfaction can be defined as the patient's

\begin{tabular}{|c|c|c|c|c|c|c|c|c|c|}
\hline Ref. & Disease & $\begin{array}{c}\text { Subjects } \\
n\end{array}$ & $\begin{array}{l}\text { Duration } \\
\text { visits }\end{array}$ & Design & $\begin{array}{l}\text { Devices } \\
\text { compared }\end{array}$ & Assessments & $\begin{array}{l}\text { Clinical } \\
\text { outcomes }\end{array}$ & Which preferred? & Sponsor \\
\hline [2] & OLD & 100 & 1 & $\begin{array}{l}\text { Instruction and } \\
\text { handling }\end{array}$ & $\begin{array}{l}7 \text { devices. All } \\
\text { placebos (?) }\end{array}$ & $\begin{array}{c}\text { Technique; 3-category } \\
\text { scoring }\end{array}$ & None & $\begin{array}{l}\text { 1) Easibreathe } e^{T M *} \\
\text { 2) Autohaler }{ }^{T M \#}\end{array}$ & None \\
\hline [3] & COPD & 20 & 1 & $\begin{array}{l}\text { Instruction and } \\
\text { handling }\end{array}$ & $\begin{array}{l}7 \text { devices. All } \\
\text { placebos (?) }\end{array}$ & $\begin{array}{l}\text { Technique score } \times 2 \text {, } \\
\text { device preference ranked }\end{array}$ & Spirometry & 1) Diskus $\left.{ }^{\circ}, 2\right)$ pMDI & None \\
\hline
\end{tabular}

OLD: obstructive lung disease; COPD: chronic obstructive pulmonary disease; pMDI: pressurised metered-dose inhaler. ?: not clear from published paper; * manufactured by Ivax, Miami, FL, USA; *: 3M Pharmaceuticals, St Paul, MN, USA; ": GlaxoSmithKline, Brentford, UK. 


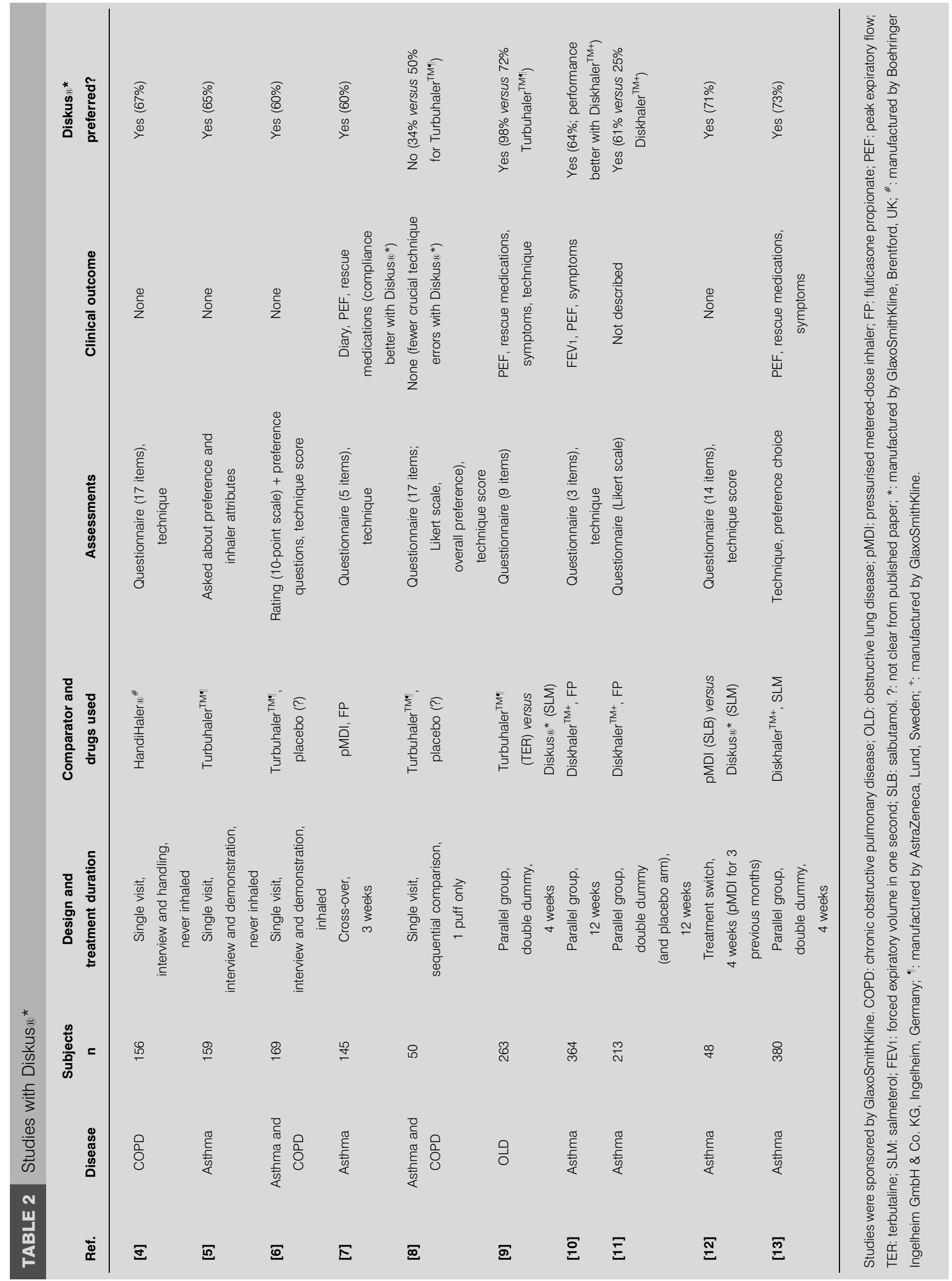




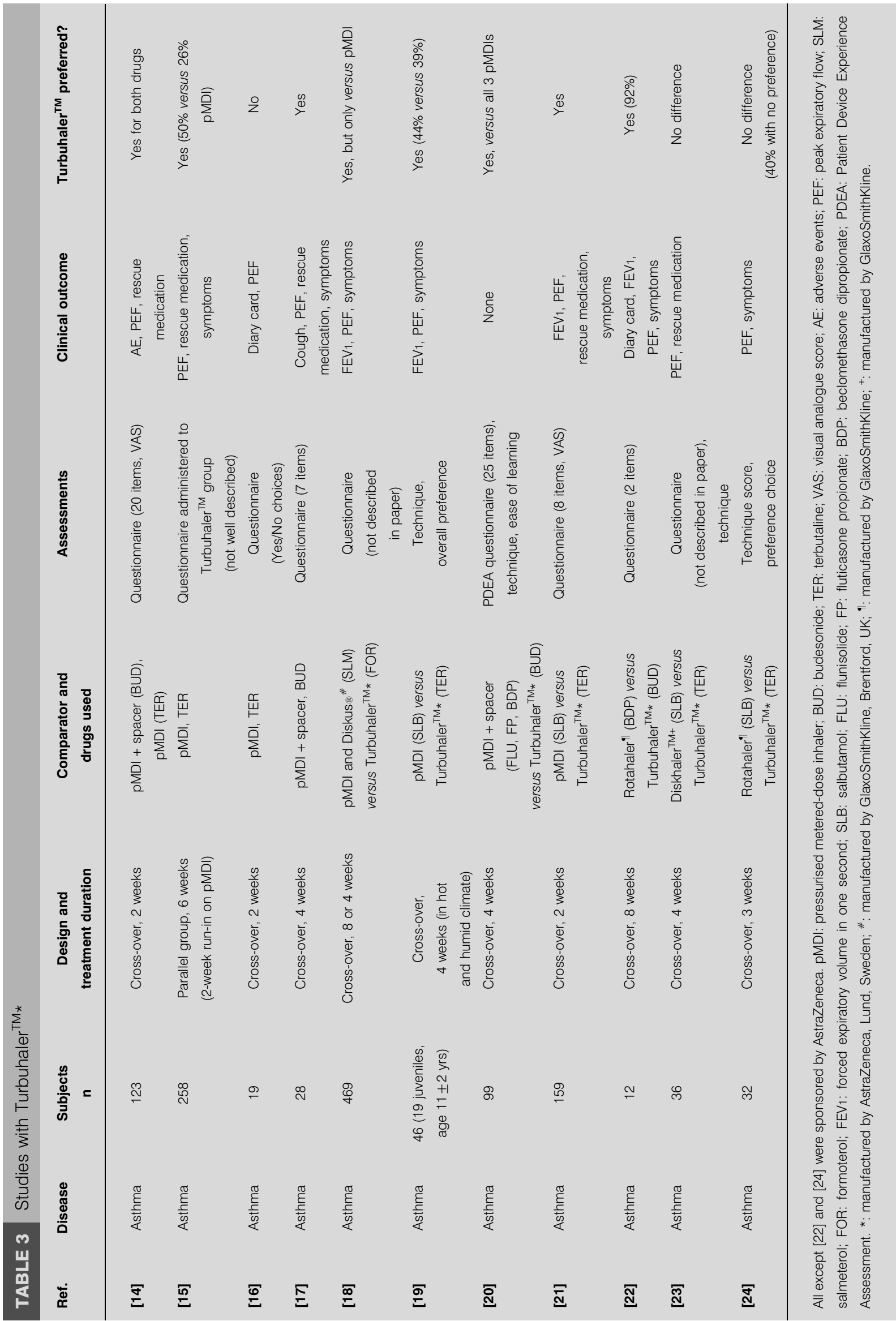




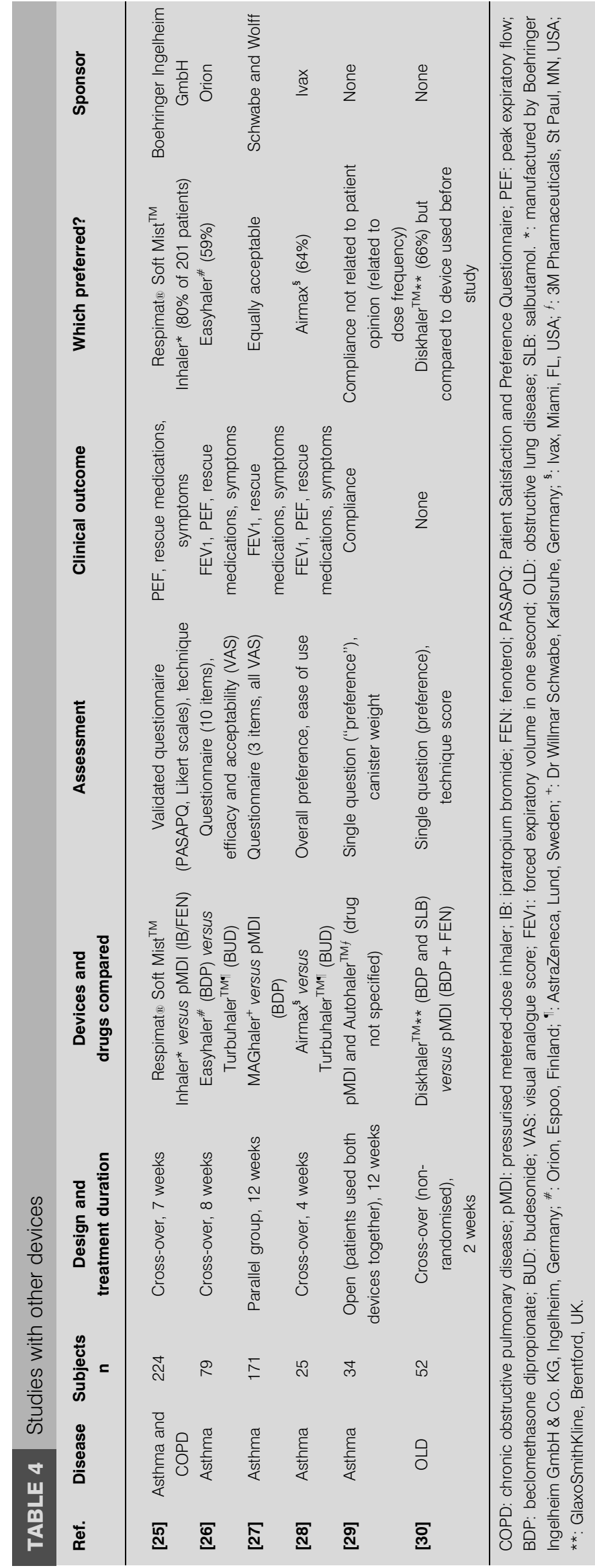

evaluation of the process of taking the medication or using the device, and the outcomes associated with these activities [31]; this definition emphasises both the process and the results. The documentation of satisfaction implies preference, which may have marketing and adherence advantages. The diagram in figure 1 shows a map of the conceptual relationships between patient-reported outcomes, including satisfaction with medication (this can be considered equivalent to satisfaction with a device), as developed by SHIKIAR and RENTZ [31]. Treatment, which includes the medication, is a major component and should have a positive impact on symptoms. A patient's satisfaction with a device will be determined in part by the extent to which they attribute improvement in symptoms to the action of the device. If the medication-device combination causes side-effects, this might negatively affect satisfaction; symptoms and side-effects also influence functional status and HRQL. There are other factors that can influence satisfaction with a device that may have nothing to do with treatment efficacy, such as ease of use, taste and portability. Figure 1 also demonstrates that patient satisfaction with a device can be altered by expectations about efficacy, which are influenced by physician communication, disease and treatment history, and direct-to-consumer marketing.

There is some information about medication satisfaction in the literature, but less on device satisfaction. ATKINSON et al. [32] developed and psychometrically evaluated a general measure of patients' satisfaction with medication; this was called the Treatment Satisfaction Questionnaire for Medication. The performance of the instrument was examined in eight patient groups with varying chronic diseases, including asthma, for

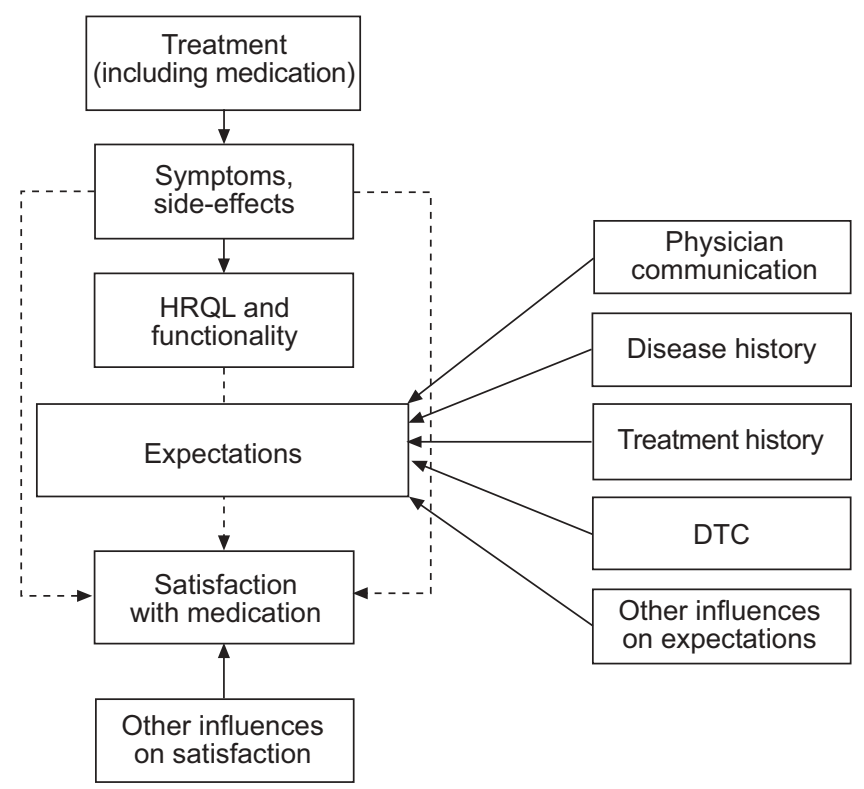

FIGURE 1. Diagram illustrating factors that can influence the patient's satisfaction with their medication (inhaler device or other treatments). Major factors are those that reflect clinical improvements attributed to the treatment, and how these match patient expectations. Patient preference may directly influence both expectations (by providing confidence in the treatment) and satisfaction, through a sense of ownership in the device selection decision. HRQL: health-related quality of life; DTC: direct-to-consumer advertising. Reproduced from [31] with permission from the publisher 


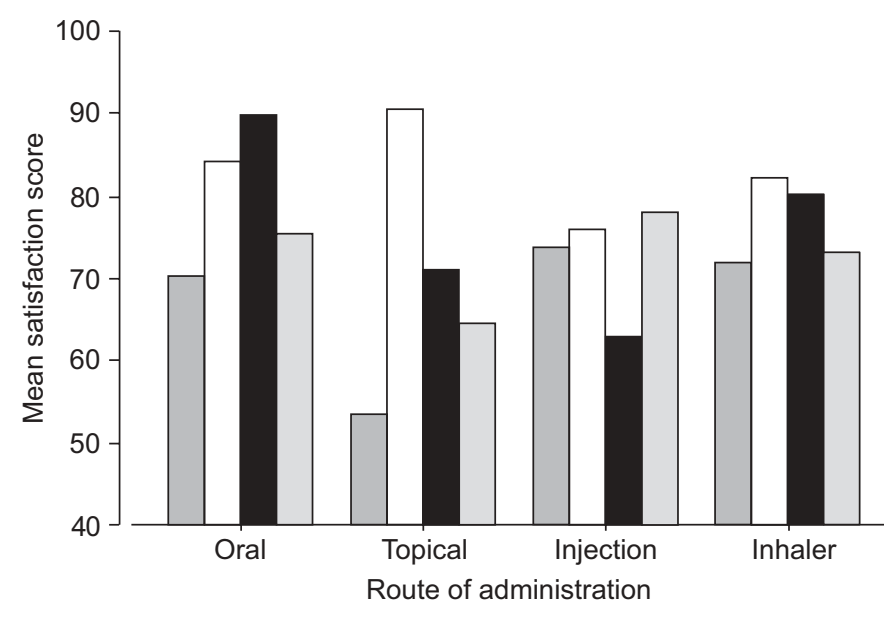

FIGURE 2. Mean satisfaction scores with treatments administered by four different routes and reported in three patient-perceived categories ( $\square$ : effectiveness; $\square$ : side-effects; $\mathbf{\square}$ : convenience) plus a global ( $\square$ : total) score. Inhalers were rated second highest for effectiveness (behind injections) and for convenience (behind oral route), but third for side-effects (behind topical and oral routes); global rating of inhalers was only slightly poorer than injection and oral routes. Reproduced from [32] with permission from the publisher.

different types of medications. Significant differences were found between the routes of administration of the medications (fig. 2) [32]. Overall satisfaction with inhalers was higher than with topical medications, but lower than with oral and injectable medications. For inhalers, the scores for convenience and lack of side-effects were slightly better than for effectiveness. Comparisons of two measuring scales (visual analogue scale and Likert scale) in these assessments, showed the Likert to have better predictive performance [32].

Development of an instrument to assess inhaler preference should be performed with the same scientific rigour as with other patient-reported outcomes. SHIKIAR and RENTZ [31] describe the following domains of satisfaction: symptom relief and efficacy, side-effects, ease and convenience, impact on HRQL and overall satisfaction. Other domains could be added to address factors specific to the disease, drug and device. In developing and validating an instrument, questions should be generated by collecting information from different sources, including patients, physicians and medical literature. The questions should be framed so as to avoid bias and should undergo psychometric analyses to establish reliability, validity and sensitivity. Pilot testing should be performed with the draft instrument in a group of representative patients. The types of instruments used in inhaler satisfaction studies to date have ranged widely, from a simple preference question to a psychometrically developed and validated questionnaire. Response scales range from open-ended questions, through unclear response scales, to visual analogue scales and Likert scales. Most of the questionnaires in the reviewed studies were developed without input from patients or experts in psychometric testing. Only two questionnaires were developed by outcomes experts and then tested in the field: the PDEA and the PASAPQ $[20,25]$. Only the PASAPQ has a published validation, which includes a determination of minimally important difference, a very important feature for discriminating the degree of difference that is clinically significant [33].

There are regulatory considerations for reporting patient preference claims concerning medications or inhaler devices. In product labelling and promotion, the same amount of scrutiny should be applied to preference claims as has been required for other patient-reported claims, such as HRQL, but to date this has not been required. Recommended requirements for quality-of-life claims have been described by LEIDY et al. [34], and specify that all relevant domains be included in an instrument and that there be a well-documented rationale for including domains. There should be evidence of reliability and validity of the instrument, with clear objectives and hypotheses (no "fishing expeditions"). The sample size should be adequate and there should be careful implementation of the study with full disclosure of results.

Besides using a validated instrument, studies comparing preference for two devices should ideally follow a randomised cross-over design, use the same drug in the devices being compared and have a treatment period of $\geqslant 2$ weeks for each device. Only six of the studies found by the search performed for this article met these criteria [7, 14, 16, 17, 25, 28]. A further problem with the preference studies reviewed in this article is that patients with unstable disease and those unable to use inhalers correctly were often excluded. It is also very difficult to do this type of study without industry support, but the results of this review may provoke the concern that negative industry-sponsored studies are not published. Patients in everyday practice may not get the type of inhaler instruction and coaching that is typical of the studies reviewed here, and these studies make no consideration of economics as a factor in choice. For these reasons, it may be somewhat difficult to extrapolate published preference data to usual clinical care.

\section{CONCLUSION}

In summary, inhaler preference is a valid patient-reported outcome worthy of scientific study. Search of the medical literature, however, shows only one rigorously developed and validated inhaler preference instrument to date. It is important that preference outcomes be subjected to the same regulatory standards as other patient-reported outcomes, but this is not the current standard. Taking device preference and satisfaction into account when choosing an inhaler device may be associated with improved clinical outcomes, but this has not been proven to date. Future research should seek to relate patient-expressed device preference to adherence, quality of life and other clinical outcomes.

\section{SUMMARY}

- Inhaler preference is a valid patient-reported outcome worthy of scientific study.

- Preference for and satisfaction with inhaler devices may be associated with improved clinical outcomes, but this has not been proven to date.

- Patients who have unstable disease or are unable to use inhalers are usually excluded from preference and 
satisfaction studies, and in everyday practice, patients rarely receive the degree of instruction and coaching given in such studies.

- Of the 29 studies found in the search performed for this article, only two used robust instruments for measuring preference and satisfaction.

- Assessment and reporting of preference and satisfaction should be subject to the same rigorous regulatory standards as other patient-reported outcomes.

\section{REFERENCES}

1 Dolovich MB, Ahrens RC, Hess DR, et al. Device selection and outcomes of aerosol therapy: Evidence-based guidelines: American College of Chest Physicians/American College of Asthma, Allergy, and Immunology. Chest 2005; 127: 335-371.

2 Lenney J, Innes JA, Crompton GK. Inappropriate inhaler use: assessment of use and patient preference of seven inhalation devices. EDICI. Respir Med 2000; 94: 496-500.

3 Oliver S, Rees PJ. Inhaler use in chronic obstructive pulmonary disease. Int J Clin Pract 1997; 51: 443-445.

4 Moore AC, Stone S. Meeting the needs of patients with COPD: patients' preference for the Diskus inhaler compared with the Handihaler. Int J Clin Pract 2004; 58: 444-450.

5 Schlaeppi M, Edwards K, Fuller RW, Sharma R. Patient perception of the Diskus inhaler: a comparison with the Turbuhaler inhaler. Br J Clin Pract 1996; 50: 14-19.

6 Serra-Batlles J, Plaza V, Badiola C, Morejon E. Patient perception and acceptability of multidose dry powder inhalers: a randomized crossover comparison of Diskus/ Accuhaler with Turbuhaler. J Aerosol Med 2002; 15: 59-64.

7 Sheth K, Bernstein JA, Lincourt WR, et al. Patient perceptions of an inhaled asthma medication administered as an inhalation powder via the Diskus or as an inhalation aerosol via a metered-dose inhaler. Ann Allergy Asthma Immunol 2003; 91: 55-60.

8 van der Palen J, Klein JJ, Schildkamp AM. Comparison of a new multidose powder inhaler (Diskus/Accuhaler) and the Turbuhaler regarding preference and ease of use. $J$ Asthma 1998; 35: 147-152.

9 Burdon J, Droszcz W, Jones R, Johnston PR, Trowell SJ. Comparison of efficacy and ease of handling of salmeterol and terbutaline powder inhalers. Int J Clin Pract 1998; 52: 85-88.

10 Pieters WR, Stallaert RA, Prins J, et al. A study on the clinical equivalence and patient preference of fluticasone propionate 250 microg twice daily via the Diskus/ Accuhaler inhaler or the Diskhaler inhaler in adult asthmatic patients. J Asthma 1998; 35: 337-345.

11 Mahajan P, Okamoto L. Patient satisfaction with the Diskhaler and the Diskus inhaler, a new multidose powder delivery system for the treatment of asthma. Clin Ther 1997; 19: $1126-1134$.

12 Liam CK, Lim KH, Wong CM. Acceptance of the Accuhaler, a multi-dose powder inhaler, among asthmatic patients: a comparison with the pressurized metered-dose inhaler. Asian Pac J Allergy Immunol 2000; 18: 135-140.

13 Boulet LP, Cowie R, Johnston P, Krakovsky D, Mark S. Comparison of Diskus inhaler, a new multidose powder inhaler, with Diskhaler inhaler for the delivery of salmeterol to asthmatic patients. Canadian Study Group. J Asthma 1995; 32: 429-436.

14 Boe J, Stiksa G, Svensson K, Asbrink E. New method of evaluating patient preference for different inhalation delivery systems. Ann Allergy 1992; 68: 255-260.

15 Osterman K, Stahl E, Kallen A. Bricanyl Turbuhaler in the treatment of asthma: a six week multi-centre study carried out in Sweden, the United Kingdom, Denmark, Norway and Finland. Eur Respir J 1991; 4: 175-179.

16 Osterman K, Norborg AM, Stahl E. A multiple dose powder inhaler (Turbuhaler) compared with a conventional aerosol. An acceptance study in asthmatics. Allergy 1989; 44: 294-297.

17 Engel T, Heinig JH, Malling HJ, et al. Clinical comparison of inhaled budesonide delivered either via pressurized metered dose inhaler or Turbuhaler. Allergy 1989; 44: 220-225.

18 Campbell LM, Anderson TJ, Parashchak MR, et al. A comparison of the efficacy of long-acting beta 2-agonists: eformoterol via Turbohaler and salmeterol via pressurized metered dose inhaler or Accuhaler, in mild to moderate asthmatics. Force Research Group. Respir Med 1999; 93 236-244.

19 Lindsay DA, Russell NL, Thompson JE, et al. A multicentre comparison of the efficacy of terbutaline Turbuhaler and salbutamol pressurized metered dose inhaler in hot, humid regions. Eur Respir J 1994; 7: 342-345.

20 Welch MJ, Nelson HS, Shapiro G, et al. Comparison of patient preference and ease of teaching inhaler technique for Pulmicort Turbuhaler versus pressurized metered-dose inhalers. J Aerosol Med 2004; 17: 129-139.

21 Vilsvik JS, Ringdal N, Albrektsen T, Holthe S. Comparison of the acceptability of the Ventolin metered-dose inhaler and the Bricanyl Turbuhaler. Ann Allergy 1993; 70: 300-304.

22 Tjwa MK. Budesonide inhaled via Turbuhaler: a more effective treatment for asthma than beclomethasone dipropionate via Rotahaler. Ann Allergy Asthma Immunol 1995; 75: 107-111.

23 Brown PH, Lenney J, Armstrong S, Ning AC, Crompton GK. Breath-actuated inhalers in chronic asthma: comparison of Diskhaler and Turbohaler for delivery of beta-agonists. Eur Respir J 1992; 5: 1143-1145.

24 Gioulekas D, Papakosta D, Vordoyianni P, Baloti H, Vamvalis C. A comparison of the clinical efficacy and patient acceptability of terbutaline Turbuhaler and salbutamol Rotahaler, in adult patients with asthma. Respir Med 1996; 90: 205-209.

25 Schurmann W, Schmidtmann S, Moroni P, Massey D, Qidan M. Respimat Soft Mist inhaler versus hydrofluoroalkane metered dose inhaler: patient preference and satisfaction. Treat Respir Med 2005; 4: 53-61.

26 Jager L, Laurikainen K, Leinonen M, Silvasti M. Beclomethasone dipropionate Easyhaler is as effective as budesonide Turbohaler in the control of asthma and is preferred by patients. German Study Group. Int J Clin Pract 2000; 54: 368-372.

27 Kunkel G, Schaper C, Noga O, et al. Efficacy, safety, and acceptance of beclomethasone dipropionate administered via a new dry powder Inhaler or a standard CFC 
metered-dose inhaler in asthma patients. Respiration 2003; 70: 399-406.

28 Frew AJ, Langley SJ, Perrin V, Hertog MG. Effects of 4week treatment with low-dose budesonide (100 micrograms BID) from a novel inhaler Airmax and from a conventional inhaler on bronchial hyper-responsiveness, lung function and symptoms in patients with mild asthma. Respir Med 2002; 96: 542-547.

29 van Schayck CP, Bijl-Hofland ID, Folgering $\mathrm{H}$, et al. Influence of two different inhalation devices on therapy compliance in asthmatic patients. Scand J Prim Health Care 2002; 20: 126-128.

30 Shieh WB. Preference for the Diskhaler rather than the metered dose inhaler in patients with airway obstruction. Changgeng Yi Xue Za Zhi 1994; 17: 20-27.
31 Shikiar R, Rentz AM. Satisfaction with medication: an overview of conceptual, methodologic, and regulatory issues. Value Health 2004; 7: 204-215.

32 Atkinson MJ, Sinha A, Hass SL, et al. Validation of a general measure of treatment satisfaction, the Treatment Satisfaction Questionnaire for Medication (TSQM), using a national panel study of chronic disease. Health Qual Life Outcomes 2004; 2: 12.

33 Kozma CM, Slaton TL, Monz BU, Hodder R, Reese PR. Development and validation of a patient satisfaction and preference questionnaire for inhalation devices. Treat Respir Med 2005; 4: 41-52.

34 Leidy N, Revicki D, Geneste B. Recommendations for evaluating the validity of quality of life claims for labeling and promotion. Value in Health 1999; 2: 113-127. 